\title{
Manejo da adubação com sulfato de amônio no desempenho produtivo do milho cultivado após aveia e trigo
}

\section{Management of ammonium sulfate fertilization on productive performance of corn grown after oats and wheat}

\author{
Maria Anita Gonçalves Silva ${ }^{1 *}$; Antonio Saraiva Muniz ${ }^{1}$; Leonardo Theodoro Bull2; \\ Anny Rosy Mannigel ${ }^{3}$; Marlene Estevão Marchetti ${ }^{4}$; Antonio Nolla ${ }^{5}$
}

\section{Resumo}

\begin{abstract}
A época de aplicação, a dose e as fontes de nutrientes fornecidos ao milho têm um efeito direto na sua produtividade. Por isso, objetivou-se estudar a aplicação de N e S no milho, como sulfato de amônio, em sucessão ao trigo e a aveia e, avaliar as diferentes formas de manejo do fertilizante. O experimento foi sob o delineamento de blocos casualizados, em Latossolo Vermelho distroférrico (Hapludox). Os tratamentos com $\mathrm{N}$, na dose de $120 \mathrm{~kg} \mathrm{ha}^{-1}$, foram aplicados em 20 parcelas $(5 \mathrm{x} 4)$, de acordo com o manejo do fertilizante: T1-N (120 kg ha-1) total na semeadura; T2-N (120 kg ha-1) total em cobertura; T3-N parcelado $\left(40 \mathrm{~kg} \mathrm{ha}^{-1}\right)$ na semeadura e $\mathrm{N}\left(80 \mathrm{~kg} \mathrm{ha}^{-1}\right)$ em cobertura; T4-N antecipadamente na semeadura do trigo e na semeadura da aveia $\left(120 \mathrm{~kg} \mathrm{ha}^{-1}\right)$; T5-testemunha (controle). As doses de $\mathrm{S}$ foram correspondentes à sua concentração no fertilizante. Somente o trigo recebeu a dose de $24 \mathrm{~kg} \mathrm{ha}^{-1}$ de $\mathrm{N}$ na semeadura em todas as parcelas e a aveia recebeu $24 \mathrm{~kg}^{-1}{ }^{-1}$ de $\mathrm{N}$ na semeadura somente nas parcelas referentes ao tratamento com antecipação do $\mathrm{N}$ do milho (T4). Foram avaliadas a produção de massa seca das culturas de inverno (aveia e trigo), em função da adubação na semeadura, e também a influência das culturas de inverno e do manejo do sulfato de amônio, na produtividade do milho. A aveia produziu mais massa seca em relação ao trigo, influenciando positivamente na produtividade do milho em sucessão, independente do manejo do fertilizante. Na rotação milho e aveia, as formas de manejo, com sulfato de amônio, na semeadura, em cobertura ou aplicado de forma parcelada foram igualmente eficientes na produtividade do milho. A antecipação do sulfato de amônio, na semeadura da aveia, foi favorável à produtividade do milho, equiparando-se às outras formas de manejo do fertilizante.

Palavras-chave: Adubação nitrogenada, adubação sulfatada, Zea mays, Avena sativa, Triticum aestivum
\end{abstract}

\begin{abstract}
The time, dose and applied nutrients in corn have a direct effect on its productivity. Therefore, the objective was to study the application of $\mathrm{N}$ and $\mathrm{S}$ in corn as ammonium sulfate, in succession to wheat and oats and evaluate different forms of fertilizer management. The experiment was conducted in a randomized block design in Oxisol (Hapludox). The five treatments with $\mathrm{N}$, at a dose of $120 \mathrm{~kg} \mathrm{ha}^{-1}$ were

${ }^{1}$ Prof. Associado do Dept ${ }^{\circ}$ de Agronomia, Centro de Ciências Agrárias, Universidade Estadual de Maringá, UEM, Maringá, PR. E-mail:magsilva@uem.br; asmuniz@uem.br

${ }^{2}$ Prof. Titular do Dept ${ }^{\circ}$ de Recursos Naturais/Ciências do Solo, Faculdade de Ciências Agronômicas, FCA, Universidade Estadual Paulista, UNESP, Botucatu, SP. E-mail: bull@fca.unesp.br

${ }^{3}$ Prof $^{a}$ do Dept ${ }^{\circ}$ Agronomia, Centro Universitário de Maringá, UniCesumar, Maringá, PR. E-mail: armannigel@unicesumar.com.br

${ }^{4}$ Prof $^{\mathrm{a}}$ Associado do Dept ${ }^{\mathrm{o}}$ de Agronomia, Faculdade de Ciências Agrárias, FCA, Universidade Federal da Grande Dourados, UFGD, Dourados, MS. E-mail: marlenemarchetti@ufgd.edu.br

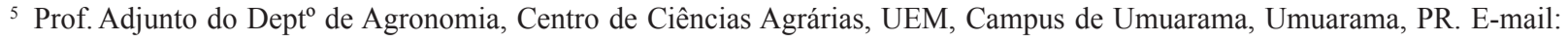
anolla@uem.br

* Autor para correspondência 
applied in 20 plots $(5 \times 4)$, according to the management of fertilizer: T1-N (120 kg ha-1) full at sowing, T2-N (120 kg ha-1) total coverage; T3 -N $\left(40 \mathrm{~kg} \mathrm{ha}^{-1}\right)$ at sowing and $\mathrm{N}\left(80 \mathrm{~kg} \mathrm{ha}^{-1}\right)$ in coverage; T4-N advance in wheat sowing and sowing oats $\left(120 \mathrm{~kg} \mathrm{ha}^{-1}\right), \mathrm{T} 5$ - (control). The $\mathrm{S}$ doses were corresponding to their concentrations in the fertilizer. Only wheat received a dose of $24 \mathrm{~kg} \mathrm{~N}^{-1}$ at sowing all plots and oats received $24 \mathrm{~kg} \mathrm{~N} \mathrm{ha}^{-1}$ at sowing only the portions related to treatment with anticipation of corn N ( T4 ). We evaluated the biomass production of winter crops (oats and wheat), according to the fertilization at sowing, and also the influence of winter crops and management of ammonium sulfate, the corn yield. The oats produced more dry matter in relation to wheat, positively influencing the corn yield, regardless of fertilizer management. The anticipation of ammonium sulfate, the sowing of oats, was favorable to corn yield, equating to other forms of management of fertilizer. Rotation corn and oats, forms management, ammonium sulphate, at seeding, topdressing or applied in split were equally efficient in corn yields.

Key words: Nitrogen fertilization, sulfur fertilization, Zea mays, Zea mays, Avena sativa, Triticum aestivum

\section{Introdução}

A área atualmente cultivada com milho no Brasil ultrapassa a casa de onze milhões de hectares, sendo que o Paraná contribui com cerca de um décimo desse total. A produtividade do milho primeira safra no Paraná, no ano de 2012, foi de 7 milhões de ton de grãos (SEAB, 2013), com um aumento de 5\% em relação ao ano anterior, mesmo sem alterar a área cultivada. Um dos fatores responsáveis por esse resultado pode estar relacionado à boas práticas de manejo, entre eles em destaque está a adubação com $\mathrm{N}$ e $\mathrm{S}$, cujos resultados são dependentes da dose, forma e época de aplicação do nutriente (BÜLL, 1993).

Em relação à adubação nitrogenada na cultura do milho, ainda se discute qual a época mais adequada para a sua aplicação. Tradicionalmente a adubação com $\mathrm{N}$ se faz utilizando parte da dose na semeadura $(1 / 3)$ e o restante (2/3) na época da cobertura, entre os estádios V4 a V8, compreendido entre 30 ou 40 dias após a emergência, considerando a alta demanda do nutriente nesta época, pois coincide com os primórdios da formação floral (FANCELLI; DOURADO NETO, 2000). Por outro lado, a manutenção da adubação de cobertura é enfatizada por Souza et al. (2012). Estudos de Soratto et al. (2010) enfatizam que a aplicação de $\mathrm{N}$ e S em cobertura, como sulfato de amônio proporcionou aumento no número espigas por planta, no número de grãos por espiga e na produtividade de grãos, cultivada sob sistema plantio direto em solo arenoso, independentemente da fonte utilizada. Da mesma forma, a aplicação de S usando como fonte o gesso superficial no plantio, foi eficiente para maximizar a produção de grãos de milho no sistema plantio direto, durante três anos (CAIRES et al., 2011).

Especificamente em relação à aplicação do $\mathrm{N}$ em plantio direto, as perdas são maiores por imobilização e volatilização (LARA CABEZAS et al., 2000; FONTOURA; BAYER, 2010), fazendo com que a resposta à adubação esteja relacionada à dose, fontes, à época de aplicação e também às culturas usadas no sistema de rotação, como a aveia e o trigo. O milho quando cultivado em sucessão ao trigo, pode responder de forma diferenciada à época da adubação nitrogenada, conforme demonstrado em estudos de Duete et al. (2009) e Cancellier et al. (2011), os quais encontraram efeito favorável no parcelamento da adubação, comparativamente à aplicação total em semeadura e/ou cobertura. Ceretta et al. (2002) e Sangoi, Ernani e Silva (2007), constataram a importância da manutenção da adubação nitrogenada em cobertura, principalmente em anos com distribuição irregular das chuvas.

Diante do exposto, objetivou-se com o trabalho: a) verificar a influência da adubação com sulfato de amônio na produção de massa seca das cultura de cobertura de inverno (aveia e trigo); b) avaliar a antecipação do sulfato de amônio do milho, na semeadura das culturas de inverno (aveia e trigo) 
para a produtividade do milho; c) relacionar formas de manejo com sulfato de amônio à produtividade no milho em sistema de rotação com trigo e aveia.

\section{Material e Métodos}

Os experimentos foram conduzidos por dois anos (2003 e 2004) na Fazenda Experimental da Cooperativa Agroindustrial (COAMO) em Campo Mourão, latitude $24^{\circ} 02^{\prime} 38^{\prime \prime}$ e longitude $52^{\circ}$
22'40" altitude de 585m, região Sul do Estado do Paraná, Brasil, em Latossolo Vermelho distroférrico (EMBRAPA, (2009a), com $600 \mathrm{~g} \mathrm{~kg}^{-1}$ de argila, cujo resultado da análise química, segundo metodologia Embrapa (1997), encontra-se na Tabela 1. Nos anos que antecederam a instalação do experimento, toda a área experimental foi cultivada com aveia, trigo e tremoço, no inverno e soja e milho no verão, em sistema plantio direto. Os dados climáticos da região durante o período de estudo encontram-se na Figura 1.

Tabela 1. Análise química do solo antes da aplicação da adubação com sulfato de amônio, em Latossolo Vermelho distroférrico (Hapludox).

\begin{tabular}{cccccccc}
\hline Prof. & $\mathrm{pH}\left(\mathrm{CaCl}_{2}\right)$ & $\mathrm{pH}\left(\mathrm{H}_{2} \mathrm{O}\right)$ & $\mathrm{Al}^{3+(1)}$ & $\mathrm{H}+\mathrm{Al}^{(2)}$ & $\mathrm{Ca}^{2+}+\mathrm{Mg}^{2+(1)}$ & $\mathrm{Ca}^{2+(1)}$ & $\mathrm{K}^{+(3)}$ \\
\hline$(\mathrm{cm})$ & & & & & $\mathrm{cmol}_{\mathrm{c}} \mathrm{dm}^{-3}$ & & \\
\hline $0-10$ & 5,1 & 5,7 & 0,00 & 4,28 & 6,04 & 4,38 & 0,33 \\
$10-20$ & 4,9 & 5,5 & 0,10 & 4,61 & 5,67 & 4,06 & 0,26 \\
\hline Prof. & $\mathrm{C}^{(4)}$ & $\mathrm{P}^{(3)}$ & $\mathrm{Fe}^{(5)}$ & $\mathrm{Zn}^{(5)}$ & $\mathrm{Cu}^{(5)}$ & $\mathrm{Mn}^{(5)}$ & $\mathrm{V}$ \\
\hline$(\mathrm{cm})$ & $\mathrm{g} \mathrm{dm}^{-3}$ & $\mathrm{mg} \mathrm{dm}$ & & & $\mathrm{mg} \mathrm{dm}^{-3}$ & & $\%$ \\
\hline $0-10$ & 22,47 & 18 & 66,00 & 22,62 & 8,39 & 53,72 & 59,81 \\
$10-20$ & 20,53 & 11 & 79,43 & 16,31 & 9,33 & 53,52 & 56,26 \\
\hline
\end{tabular}

(1) extrator KCl 1 M; (2) método SMP; (3) Mehlich1; (4) Walkley- Black

(5) extrator utilizado para micronutrientes: Mehlich1, com filtragem após decantação de 16 horas.

Fonte: Embrapa (1997).

Durante dois anos de estudo foram cultivados, no período de inverno, o trigo e a aveia, culturas essas que antecederam o cultivo do milho, nas mesmas áreas ou parcelas experimentais. O trigo nos dois anos de estudo recebeu $300 \mathrm{~kg} \mathrm{ha}^{-1}$ do formulado 08-30-20, fornecendo desta forma na semeadura $24 \mathrm{~kg} \mathrm{~N} \mathrm{ha}^{-1} ; 90 \mathrm{~kg} \mathrm{P}_{2} \mathrm{O}_{5}$ há $^{-1}$ e $60 \mathrm{~kg} \mathrm{~K} \mathrm{O}$ ha $^{-1}$ (OLIVEIRA, 2003; TEDESCO et al., 2004; EMBRAPA, 2009b; GARBUGLIO, 2013). Neste caso, a dose de $\mathrm{N}$ aplicada na semeadura foi de 24 $\mathrm{kg} \mathrm{ha}^{-1}$ e correspondeu a um primeiro tratamento, que foi o mesmo em 12 parcelas. No segundo tratamento (quatro parcelas), o trigo recebeu a adubação com $\mathrm{N}$ na semeadura $\left(24 \mathrm{~kg} \mathrm{ha}^{-1}\right.$ somado a $120 \mathrm{~kg} \mathrm{ha}^{-1}$, antecipando todo o $\mathrm{N}$ que seria aplicado no milho, num total de $144 \mathrm{~kg} \mathrm{ha}^{-1}$ ). O terceiro tratamento (quatro parcelas) foi o tratamento controle, onde o trigo não recebeu a adubação com sulfato de amônio. A área com trigo foi conduzida no sistema de blocos casualizados e constituiu-se de 20 parcelas com $20 \mathrm{~m}^{2}$, as quais irão receber o milho, no verão, sob diferentes formas de manejo do sulfato de amônio. As parcelas continham 30 linhas de $4,0 \mathrm{~m}$ de comprimento, espaçadas com $0,17 \mathrm{~m}$ entre as linhas $(5 \mathrm{~m} \mathrm{x} 4 \mathrm{~m})$ ou área da parcela total de $20 \mathrm{~m}^{2}$. A semeadura do trigo cv CD 104 ocorreu na primeira semana de Abril de 2003 e 2004, utilizando 320 sementes por $\mathrm{m}^{2}$. A cultura permaneceu no campo até a produção dos grãos. As cinco linhas centrais do trigo foram usadas para as avaliações de produção de biomassa. Concomitantemente à semeadura do trigo foi realizada a semeadura da aveia. A aveia foi semeada em 16 parcelas, sem receber nenhuma adubação. A cultura recebeu adubação somente em um tratamento, na dose de 24 $\mathrm{kg} \mathrm{ha}^{-1}$ de $\mathrm{N}$ somado a $120 \mathrm{~kg} \mathrm{ha}^{-1}$ de $\mathrm{N}$ antecipados 
do milho, totalizando $144 \mathrm{~kg} \mathrm{ha}^{-1}$ de $\mathrm{N}$ na semeadura (quatro parcelas). A área com a aveia foi conduzida no sistema de blocos casualizados, totalizando 20 parcelas de $20 \mathrm{~m}^{2}$, parcelas estas que receberam o milho diferentemente adubado, em sucessão ou no período do verão. A população foi de 45-60 plantas por metro linear e um espaçamento entre linhas de 0,15m distribuídas em 30 linhas de 4,0 m, com 320 sementes $\mathrm{m}^{2}(5 \mathrm{~m} \times 4 \mathrm{~m})$ e um total de $20 \mathrm{~m}^{2}$. As cinco linhas centrais das parcelas com aveia foram usadas para a avaliação da produção de biomassa. Toda a área com a aveia foi adubada com $60 \mathrm{~kg} \mathrm{P}_{2} \mathrm{O}_{5}$ ha- ${ }^{1}$ e $60 \mathrm{~kg} \mathrm{~K}_{2} \mathrm{O}$ ha $^{-1}$ (300 $\mathrm{kg} \mathrm{ha}^{-1}$ da fórmula 0-2020), estabelecida por Embrapa (2000).

Figura 1. Precipitação pluvial e temperatura média anuais durante o período de condução das culturas, na Fazenda Coamo, Campo Mourão, Estado do Paraná (2003-2005).

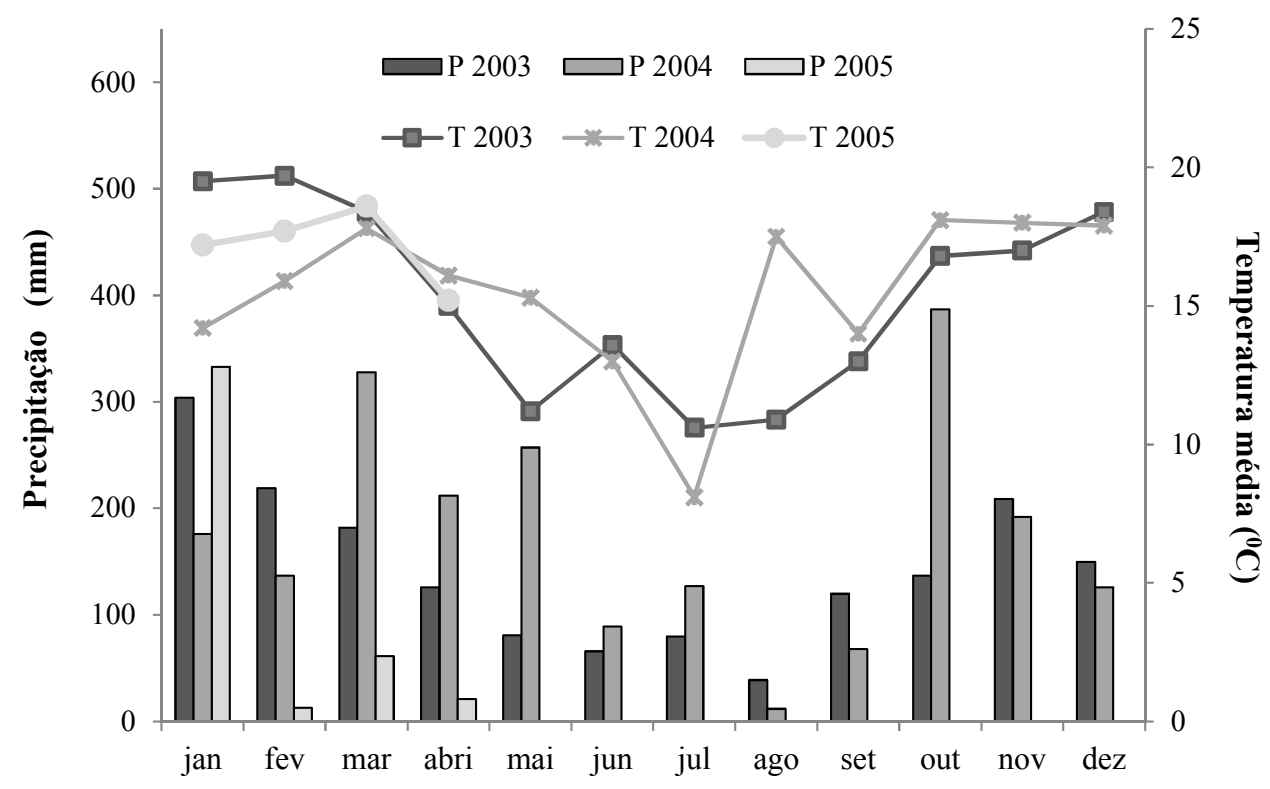

Fonte: Cooperativa Agroindustrial de Campo Mourão, COAMO, PR.

No primeiro ano, a aveia foi dessecada utilizando Glyphosato, 100 dias após a semeadura, quando nas plantas $50 \%$ das sementes estavam no estádio de grão leitoso; no ano seguinte, as plantas receberam o mesmo herbicida, 130 dias após a semeadura, quando $75 \%$ das sementes atingiram o mesmo estádio.

Durante dois anos, no período de verão, nas mesmas áreas cultivadas com as culturas de inverno (aveia e trigo), foi cultivado o milho. No primeiro ano, o genótipo de milho (Pioneer 30P70), foi semeado no final de outubro e no segundo ano a semeadura ocorreu em Novembro, sendo utilizado o híbrido Syngenta. Nos dois anos a cultura recebeu na época da semeadura uma adubação básica com P e K (300 kg ha-1 de 00-20-10), de acordo com EMBRAPA (2007). As parcelas apresentaram área de $20 \mathrm{~m}^{2}$ e foi constituída de um arranjo espacial com cinco linhas de milho espaçadas de $1 \mathrm{~m}$, com 4,0 $\mathrm{m}$ de comprimento (aproximadamente 45.000 plantas ha' $\mathrm{h}^{-1}$.

O delineamento experimental para o milho foi de blocos casualizados, com cinco tratamentos e quatro repetições, totalizando 20 parcelas. Os tratamentos avaliaram o manejo da adubação com sulfato de amônio no milho, com total de $\mathrm{N}$ de 120 $\mathrm{kg} \mathrm{ha}^{-1}$, cujas formas de manejo com o N (sulfato de amônio) foram: aplicação na semeadura, na época 
da cobertura, quatro semanas após a emergência ou parcelados na semeadura e na cobertura do milho. Além disso foi avaliada a antecipação da adubação nitrogenada do milho, a qual foi aplicada na semeadura da cultura de inverno, aveia ou trigo. Os tratamentos com N (sulfato de amônio) no trigo e milho compreenderam: T1: 24-120- 0; T2: $24-0$ 120; T3: 24- 40- 80; T4: 144- 0- 0 e T5: 0- 0- 0, os quais corresponderam respectivamente à adubação na semeadura do trigo (no inverno), adubação na semeadura do milho (verão) e em cobertura do milho (verão). Os tratamentos com $\mathrm{N}$ na aveia e milho compreenderam: T1: $0-120-0$; T2: $0-0-$ 120; T3: 0 - 40 - 80; T4: $144-0-0$ e T5: $0-0-0$, respectivamente, adubação na semeadura da aveia, na semeadura do milho e em cobertura do milho. As doses de $\mathrm{S}$ foram aplicadas, concomitantemente ao $\mathrm{N}$, em função da concentração do nutriente no fertilizante (sulfato de amônio).

Ao final do período de inverno, foram avaliadas a produção da massa seca da aveia e do trigo, em parcelas de $1,0 \mathrm{~m}^{2}$, após a pesagem das plantas secas. Para a avaliação da produção da massa seca do milho foram utilizadas 20 plantas das duas linhas centrais de cada parcela, num total de 400 plantas de milho em todas as parcelas.

Para a avaliação da produtividade foram coletadas as espigas de toda a parcela manualmente, separados os grãos, os quais foram pesados após determinação da umidade e a massa foi determinada considerando uma umidade de $13 \%$, extrapolado para $\mathrm{kg} \mathrm{ha}^{-1}$.

Os resultados foram submetidos à analise de variância e as médias referentes ao manejo da adubação nitrogenada foram comparadas pelo teste Tukey a 5\% de probabilidade, utilizandose o programa SISVAR para a análise estatística (FERREIRA, 2000).

\section{Resultados e Discussão}

\section{Produção de fitomassa da aveia e do trigo}

A produção de massa seca da aveia que recebeu sulfato de amônio na semeadura (144 kg $\mathrm{ha}^{-1} \mathrm{~N}$ ) foi maior que a do trigo, que recebeu, na semeadura, a mesma quantidade de $\mathrm{N}\left(144 \mathrm{~kg} \mathrm{ha}^{-}\right.$ ${ }^{1}$ ), nos dois anos de cultivo (Figura 2). A massa seca da aveia adubada foi maior no primeiro ano, quando apresentou melhor resultado $\left(12300 \mathrm{~kg}\right.$ ha $^{-}$ ${ }^{1}$ ), comparada ao trigo (9000 $\left.\mathrm{kg} \mathrm{ha}^{-1}\right)$, mesmo no tratamento sem adubação. Segundo Santi, Amado e Costa (2003), a adubação nitrogenada aumenta de forma quadrática a produção de matéria seca da aveia, onde a produção máxima foi de $7171 \mathrm{~kg}$ $\mathrm{ha}^{-1}$, com a dose de $180 \mathrm{~kg} \mathrm{ha}^{-1}$ de N. Estudos de Melo et al. (2011), verificaram melhor produção de massa seca da aveia, quando adubada com $\mathrm{N}$ na semeadura e em cobertura (62 kg ha $\mathrm{kg}^{-1} 124 \mathrm{~kg} \mathrm{ha}^{-1}$ ), respectivamente a cultura produziu $1299 \mathrm{~kg} \mathrm{ha}^{-1} \mathrm{e}$ $3000 \mathrm{~kg} \mathrm{ha}^{-1}$ de massa seca.

Quando a aveia não foi adubada, a quantidade de massa variou entre $5500 \mathrm{~kg} \mathrm{ha}^{-1}$ a $7000 \mathrm{~kg}$ ha $^{-}$ 1 , nos dois anos, bem acima da encontrada em outros trabalhos realizados em plantio direto, cuja produção de matéria seca esteve em $4000 \mathrm{~kg} \mathrm{ha}^{-1}$, semelhante a Silva et al. (2009). Por outro lado, Silva et al. (2008) obtiveram massa seca da parte aérea da aveia preta de $3600 \mathrm{~kg} \mathrm{ha}^{-1}$ a $8300 \mathrm{~kg} \mathrm{ha}^{-1}$ após adubação nitrogenada de $40 \mathrm{~kg} \mathrm{ha}^{-1}$ e $60 \mathrm{~kg}$ $h^{-1}$ de N nos estádios V4-V5 e estádios V9-10, num primeiro ano de estudo e adubação com $\mathrm{N}$ de $70 \mathrm{~kg}$ $h^{-1}$ e $110 \mathrm{~kg} \mathrm{ha}^{-1}$, nos estádios V3-4 e estádios V910 , num segundo ano de estudo.

A massa seca do trigo adubado com sulfato de amônio na semeadura esteve entre $7000 \mathrm{~kg} \mathrm{ha}^{-1} \mathrm{a}$ $9000 \mathrm{~kg} \mathrm{ha}^{-1}$, nos tratamentos adubados (Figura 2), superiores às observadas por Silva et al. (2008), Meneghin et al. (2008) e Megda et al. (2009), os quais avaliaram respostas à adubação nitrogenada em trigo. Silva et al. (2008), após dois anos de estudo, obtiveram valores de massa seca da parte aérea, incluindo os grãos entre $3,3 \mathrm{Mg} \mathrm{ha}^{-1}$ a 4,5 $\mathrm{Mg} \mathrm{ha}^{-1}$. Por outro lado, Ozorio Filho et al. (2007), não encontraram resposta no crescimento do trigo, quando aplicaram até $60 \mathrm{~kg} \mathrm{ha}^{-1}$ de $\mathrm{S}$ em Latossolo Vermelho distrófico. De acordo com os autores o $\mathrm{S}$ proveniente das chuvas e da decomposição da 
matéria orgânica é suficiente para um suprimento adequado pelas culturas, podendo não ocorrer resposta quando adubadas.

A resposta favorável do trigo, em produção de massa seca, quando o sulfato de amônio foi aplicado todo na semeadura, pode ser atribuída ao efeito favorável do $\mathrm{N}$ (144 $\left.\mathrm{kg} \mathrm{ha}^{-1}\right)$ junto com o S (173 $\mathrm{kg} \mathrm{ha} \mathrm{a}^{-1}$ ), embora o trigo tenha respondido às doses bem mais baixas de $\mathrm{S}$, como demonstram estudos de Oates e Kamprath (1985), tendo como uma das fontes estudadas o sulfato de amônio, cuja dose de $20 \mathrm{~kg} \mathrm{ha}^{-1}$ de $\mathrm{S}$ fez o trigo apresentar a melhor resposta em crescimento de fitomassa.
Meneghin et al. (2008), estabeleceram quantidades entre $78 \mathrm{~kg} \mathrm{ha}^{-1}$ a $114 \mathrm{~kg} \mathrm{ha}^{-1}$, como doses mais econômicas de $\mathrm{N}$ (sulfato de amônio), aplicadas na semeadura da cultura. Teixeira Filho et al. (2010) verificaram também que a aplicação de N total na semeadura ou de forma parcelada, no trigo foram igualmente viáveis, e o sulfato de amônio foi uma das fontes estudadas. O incremento da dose do fertilizante até $121,5 \mathrm{~kg} \mathrm{ha}^{-1}$, na semeadura, em média incrementou o crescimento e a produtividade de grãos do trigo.

Figura 2. Produção de massa seca do trigo (sem panícula) e da aveia (sem panícula), em função do manejo do sulfato de amônio (na semeadura do trigo/aveia, na semeadura do milho e na cobertura do milho. No mesmo ano, médias com letras minúsculas entre os tratamentos e letras maiúsculas, entre as culturas, foram estatisticamente diferentes a 5,0\% de probabilidade pelo Teste de Scott-Knott.

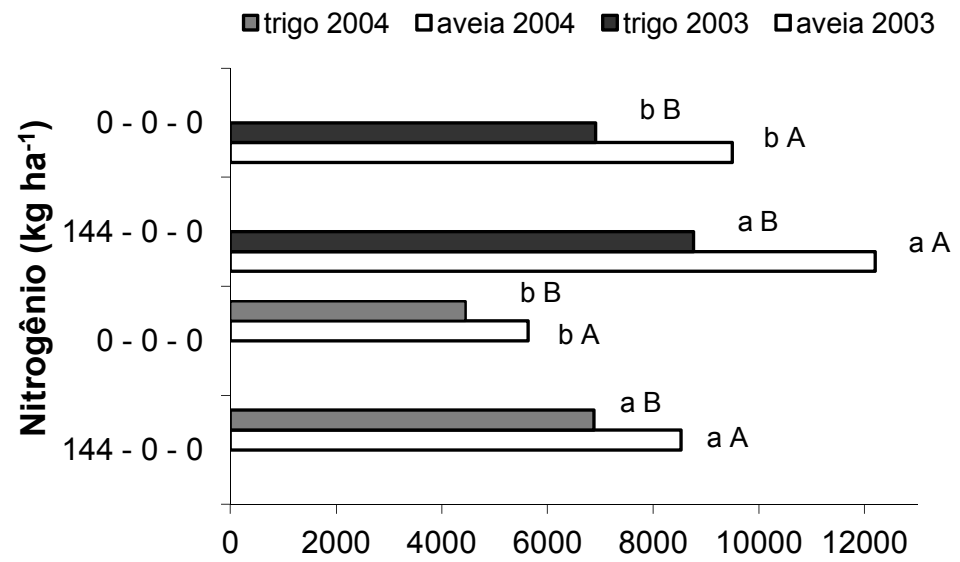

Massa seca do trigo e da aveia (kg ha-1)

Fonte: Elaboração dos autores.

Produção de fitomassa do milho após as culturas de inverno

O manejo da adubação com sulfato de amônio no milho, após cultivo do trigo e aveia, durante dois anos agrícolas, influenciou a produção de fitomassa do milho enquanto que a produtividade foi influenciada tanto pelo manejo do fertilizante quanto pelas culturas de inverno, aveia e trigo (Tabela 2). Corroborando, os resultados de Gava et al. (2010) observaram que a elevação da dose de $\mathrm{N}$ em cobertura, proveniente do sulfato de amônio, resultou no aumento da massa seca do milho, assim como na produtividade e acúmulo de $\mathrm{N}$ pelas plantas. Da mesma forma, as plantas do primeiro cultivo de milho e aveia preta aumentaram a produção de matéria seca com a aplicação de $\mathrm{S}$, em Tiecher et al. (2012), mas o aumento da produção do milho não teve relação com os teores de $\mathrm{S}$ disponível da camada $0-10 \mathrm{~cm}$ nos solos arenosos. 
Tabela 2. Análise de variância para massa seca total e produtividade do milho cultivado após trigo e milho após aveia, submetido ao manejo da adubação com sulfato de amônio em plantio direto.

\begin{tabular}{lrrrrr}
\hline \multicolumn{5}{c}{$\mathbf{2 0 0 3 / 2 0 0 4}$} & \multicolumn{2}{c}{ Valor de F } \\
\hline Fonte de variação & GL & $\begin{array}{c}\text { Massa seca } \\
\text { total }\end{array}$ & Produtividade & Massa seca total & Produtividade \\
\hline Manejo (M) & 4 & $11,941^{* *}$ & $57,659^{* *}$ & $7,992 * *$ & $15,793^{* *}$ \\
Cultura (C) & 1 & $0,005 \mathrm{~ns}$ & $95,049^{* *}$ & $1,427 \mathrm{~ns}$ & $2,498 \mathrm{~ns}$ \\
M*C & & $2,601 \mathrm{~ns}$ & $2,248^{*}$ & $1,627 \mathrm{~ns}$ & $15,290^{* *}$ \\
C.V. & - & 11,51 & 5,39 & 14,52 & 10,09 \\
Média Geral & - & $13,643,30$ & 7876.05 & 8642,75 & 4053,45 \\
& & & & & \\
\hline
\end{tabular}

Fonte: Elaboração dos autores.

$\mathrm{Na}$ primeira safra $(2003 / 2004)$, ocorreu maior crescimento do milho, expresso pela produção de massa seca (Figura 3), comparativamente à segunda safra (2004/2005), independente da cultura anterior e também da forma de manejo do fertilizante, comparativamente ao tratamento controle o que pode ser atribuído pela distribuição mais regular das chuvas (Figura 3), bem como à cultivar usada, que pode ter sido mais responsiva ao fertilizante. Por outro lado, no segundo cultivo, ocorreu melhor resultado nos tratamentos onde foi feita a aplicação do N no milho, independente de ser na semeadura, na cobertura ou de forma parcelada, comparativamente à antecipação do $\mathrm{N}$ na época da semeadura do trigo ou da aveia (Figura 3). Possivelmente, neste ano, a irregularidade das chuvas pode ter diminuido a eficiência de decomposição e liberação dos nutrientes ao milho, quando a adubação nitrogenada foi antecipada nas culturas de inverno.

As culturas de inverno (aveia e trigo) tiveram igual influência na produção da fitomassa do milho (Tabela 2), discordando dos estudos de Costa et al. (2011), os quais relatam que o cultivo de milho em sucessão ao trigo proporciona a um maior crescimento e produtividade da cultura, quando relacionada à aveia consorciada com ervilhaca e nabo forrageiro, como culturas anteriores.

Figura 3. Produção de massa seca da parte aérea do milho, após trigo e aveia em função do manejo do sulfato de amônio na sequência: $\mathrm{N}$ na semeadura do trigo $\left(24 \mathrm{~kg} \mathrm{ha}^{-1}\right)$ ou na semeadura da aveia, somente na dose de $144 \mathrm{~kg}$ ha $^{-1\left(^{*}\right)}$; N na semeadura do milho; $\mathrm{N}$ na cobertura do milho. No mesmo ano, médias com letras minúsculas entre os tratamentos e letras maiúsculas no tratamento, foram estatisticamente diferentes a 5,0 \% de probabilidade pelo Teste de Scott-Knott.

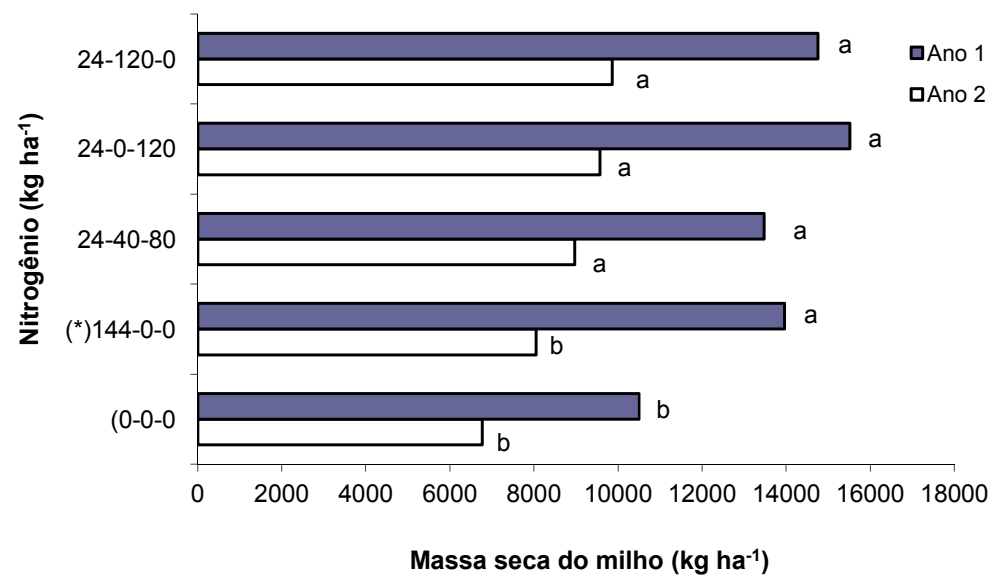

Fonte: Elaboração dos autores. 
Produtividade do milho, após as culturas de inverno, em função do manejo do fertilizante

Em 2003/2004, a maior produtividade do milho após o trigo, ocorreu quando a adubação foi aplicada toda na semeadura ou toda em cobertura no milho (Figura 4A), comparativamente à adubação parcelada ou realizada de forma antecipada, na semeadura das culturas de inverno. Tal resultado, todavia, não se repetiu no milho após à aveia, onde as produções estiveram bem próximas, em todas as formas de manejo, inclusive quando houve a antecipação do N (144 kg há-1) na semeadura da aveia. Os resultados podem estar relacionados ao incremento na produção de massa seca da aveia, comparada ao trigo (Figura 2), que pode ter favorecido a produção do milho. Exceção ocorreu na testemunha, sem o sulfato de amônio, que trouxe como consequência a mais baixa produtividade do milho. Os resultados não corroboram com Duete et al. (2009), os quais observaram melhor resposta na produtividade quando o milho teve a adubação nitrogenada parcelada (135 kg ha-1) em Hapludox, aos 20, 40 e 60 dias após a emergência. Por outro lado, Silva et al. (2011) obtiveram melhor resultado na produtividade do milho, com o parcelamento do $\mathrm{N}$ ou com toda a adubação nitrogenada foi realizada na semeadura do milho.

Por outro lado Oliveira e Caires (2003) encontraram alta produtividade do milho cultivado após a aveia preta $\left(8366 \mathrm{~kg} \mathrm{ha}^{-1}\right)$, para a dose de $120 \mathrm{~kg} \mathrm{ha}^{-1}$ de N, aplicada em cobertura. Da mesma forma, Sangoi, Ernani e Silva (2007) relacionam a adubação nitrogenada em cobertura, como uma das práticas de manejo que melhor se relacionaram à produtividade do milho após o cultivo da aveia.
Os resultados são concordantes com os de Lara Cabezas e Souza (2008) e Soratto et al. (2010) os quais demonstraram que o milho apresentou alta produtividade quando recebeu $\mathrm{N}$ e $\mathrm{S}$ em cobertura, como sulfato de amônio, comparativamente a outras formas de fertilizantes contendo os nutrientes.

No segundo ano, o manejo do sulfato de amônio influenciou a produtividade do milho após o cultivo com aveia (Figura 4B) e o melhor tratamento foi quando toda a adubação ocorreu na semeadura do milho. Por outro lado, no milho após o trigo, todas as formas de manejo do fertilizante incrementaram a produtividade, comparativamente à testemunha sem o fertilizante. Neste ano, o milho produziu de forma semelhante, mesmo quando toda a adubação nitrogenada foi antecipada na semeadura das culturas de inverno (144kg ha-1 de $\mathrm{N}$ ), que pode estar associada às quantidades de biomassa do trigo e da aveia, as quais apresentaram resultados mais próximos (Figura 2). Tais resultados corroboram com Silva et al. (2007) cujo melhor desempenho do milho em produção ocorreu na aplicação parcelada do $\mathrm{N}$ ou todo em cobertura do milho após a aveia preta, em solos do Rio Grande do Sul. Ferreira et al. (2009) aplicaram 40,5 $\mathrm{kg} \mathrm{ha}^{-1}$ de $\mathrm{N}$ na semeadura e o restante em cobertura, nas doses complementares a $60 \mathrm{~kg} \mathrm{ha}^{-1}, 120 \mathrm{~kg} \mathrm{ha}^{-1}, 180 \mathrm{~kg} \mathrm{ha}^{-1}$ e $240 \mathrm{~kg} \mathrm{ha}^{-1}$ de $\mathrm{N}$ e concluíram que o aumento das doses de $\mathrm{N}$ promoveu um suprimento adequado de $\mathrm{N}$ ao milho $\mathrm{e}$ melhorou a produtividade, em todos os tratamentos com palha de aveia preta.

Neste segundo ano, os resultados de produtividade do milho estiveram bem abaixo do ano anterior, provavelmente devido a variação nos híbridos de milho utilizados, que podem apresentar diferentes potenciais produtivos, bem como à ocorrência irregular de chuvas, associada à uma alta variação nas temperaturas mensais, em todo o período de avaliação (Figura 1). 
Figura 4. Produtividade do milho após trigo e após aveia, em função do manejo do sulfato de amônio (na semeadura do trigo e da aveia, na semeadura e na cobertura do milho.
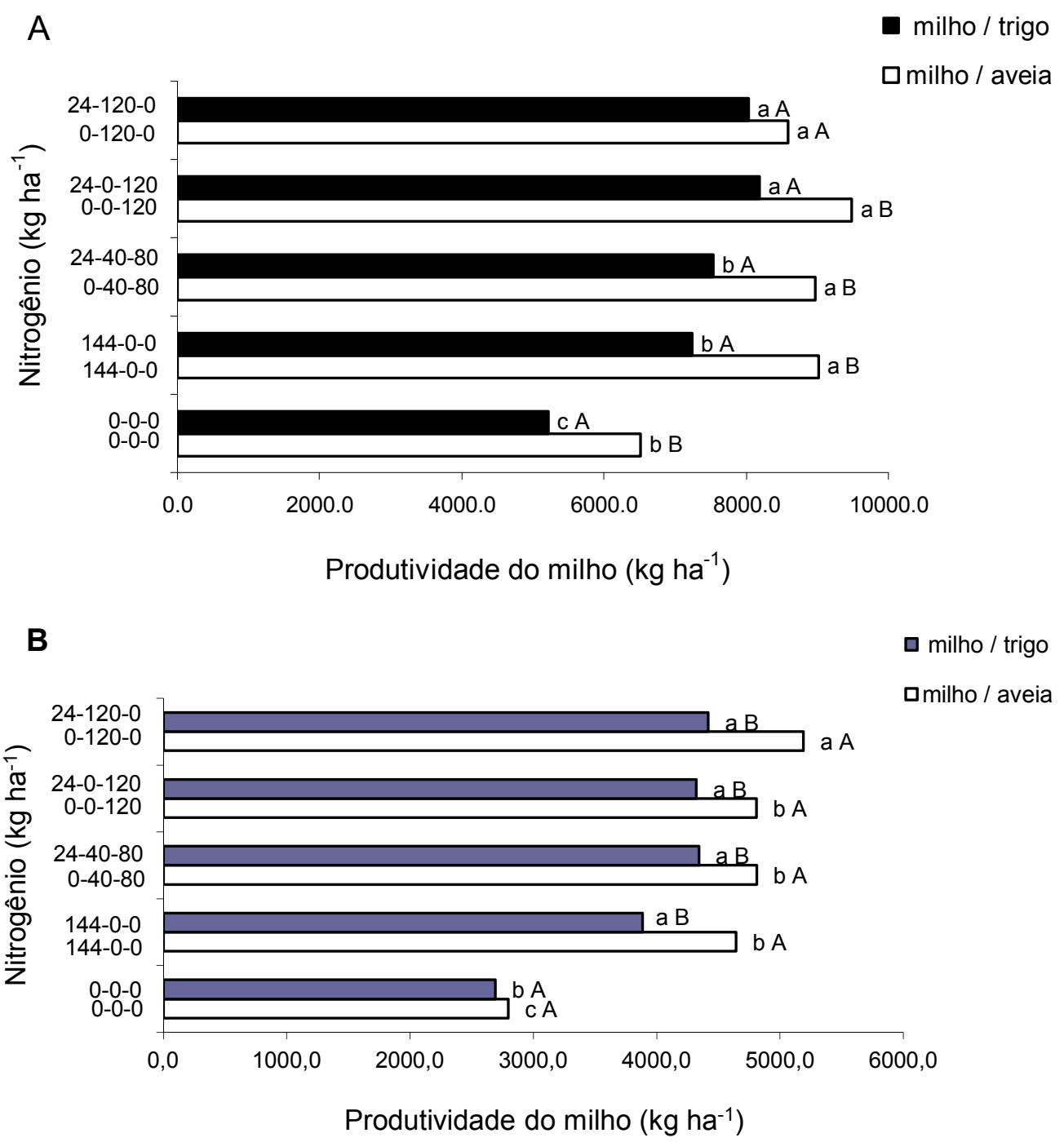

(A) 2003/2004 e (B) 2004/2005. Considerando a mesma rotação de cultura, médias com letras minúsculas, entre os tratamentos e letras maiúsculas, entre as rotações, foram estatisticamente diferentes a 5,0\% de probabilidade pelo Teste de Scott-Knott.

Fonte: Elaboração dos autores.

Nos dois anos agrícolas, o milho cultivado após a aveia produziu mais do que quando cultivado após o trigo, provavelmente devido ao alto crescimento e produção de massa seca da aveia, além do sistema radicular mais agressivo, que pode ter influenciado na reciclagem de nutrientes, os quais podem ter sido absorvidos e beneficiado o crescimento do milho (Figura 4A e 4B). Além disso, a ocorrência irregular das chuvas, neste ano, acentuou ainda mais a importância da deposição da massa orgânica da aveia, a qual pode ter contribuído para melhorar o desempenho do fertilizante, numa condição de umidade desfavorável. De forma semelhante, o efeito favorável da aveia na produtividade do milho foi descrito por Muraishi et al. (2005) e Caires et al. (2006). Silva et al. (2012) demonstraram uma relação direta entre a produtividade do milho e o número de espigas ha-1 ${ }^{-1}$, bem como com o comprimento e a massa das espigas, quando cultivado após a aveia preta e ao trigo, em sistema plantio direto. 


\section{Conclusões}

A aveia produziu mais massa seca da parte aérea e favoreceu a produtividade do milho em sucessão, comparativamente ao trigo, independente do manejo com sulfato de amônio;

Na rotação milho e aveia, as formas de manejo do sulfato de amônio, na semeadura, em cobertura ou de forma parcelada foram igualmente eficientes na produtividade do milho;

A antecipação do sulfato de amônio do milho, na semeadura da aveia, favoreceu a produtividade do milho, comparada às outras formas de manejo do fertilizante.

\section{Agradecimentos}

Agradecemos a COAMO Agroindustrial Cooperativa de Campo Mourão, e em especial ao Engenheiro Agrônomo Joaquim Mariano Costa, chefe da fazenda experimental da Cooperativa COAMO, em Campo Mourão, que muito contribuiu para que esta pesquisa pudesse ser realizada e seus resultados concretizados.

\section{Referência}

BÜLL, L. T. Nutrição mineral do milho. In: BÜLL, L. T.; CANTARELLA, H. A cultura do milho: fatores que influenciam no rendimento. Piracicaba: Associação Brasileira para Pesquisa da Potassa e do Fosfato, 1993. p. 63-121.

CAIRES, E. F.; GARBUIO, F. J.; ALLEONI, L. R. F.; CAMBRI, M. A. Calagem superficial e cobertura de aveia preta antecedendo os cultivos de milho e soja em plantio direto. Revista Brasileira de Ciência do Solo, Viçosa, MG, v. 30, n. 1, p. 87-98, 2006.

CAIRES, E. F.; MASCHIETTO, E. H. G.; GARBUIO, F. J.; CHURKA, S.; JORIS, H. A. W. Aplicação superficial de gesso num Latossolo de baixa acidez sob sistema plantio direto. Scientia Agricola, Piracicaba, v. 68, n. 2, p. 209-216, 2011.

CANCELLIER, L. L.; AFFÉRRI, F. S.; ADORIAN, G. C.; RODRIGUES, H. V. M.; MELO, A. V.; PIRES, L. P. M.; CANCELLIER, E. L. Adubação orgânica na linha de semeadura no desenvolvimento e produtividade do milho. Semina: Ciências Agrárias, Londrina, v. 32, n. 2, p. 527-540, 2011.

CERETTA, C. A.; BASSO, C. J.; DIEKOW, J.; AITA, C.; PAVINATO, P. S.; VIEIRA, F. C. B.; VENDRUSCLO, E. R. O. Nitrogen fertilizer split-application for corn in no-tillage sucession to black oats. Scientia Agricola, Piracicaba, v. 59, n. 3, p. 549-554, 2002.

COSTA, M. S. S. M.; STEINER, F.; COSTA, L. A. M.; CASTOLDI, G.; PIVETTA, L. A. Nutrição e produtividade da cultura do milho em sistemas de culturas e fontes de adubação. Revista Ceres, Viçosa, MG, v. 58, n. 2, p. 249-255, 2011.

DUETE, R. R. C.; MURAOKA, T.; SILVA, E. C.; AMBROSANO, E. J.; TRIVELIN, P. C. O. Acúmulo de $\left({ }^{15} \mathrm{~N}\right)$ pelos grãos de milho em função da fonte nitrogenada em Latossolo Vermelho, Bragantia, Campinas, v. 68, n. 2, p. 463-472, 2009.

EMPRESA BRASILEIRA DE PESQUISA AGROPECUÁRIA - EMBRAPA. Centro Nacional de Pesquisa de Solos. Manual de métodos de análise de solo. 2. ed. Rio de Janeiro: Embrapa-Solos, 1997. 212 p.

Recomendações técnicas para o cultivo da aveia. Embrapa Pecuária Sudeste. Boletim de pesquisa $\mathrm{n}^{\circ} 6.2000 .39 \mathrm{p}$.

Centro Nacional de Pesquisa de Solos. Cultivo do milho. Nutrição e adubação do milho. Sete Lagoas. EMBRAPA, 2007. 11 p. (Sistema de Produção Circular, n. 96).

Centro Nacional de Pesquisa de Solos. Sistema Brasileiro de Classificação de Solos. Rio de Janeiro: EMBRAPA, 2009. 412 p. 2009a.

Centro Nacional de pesquisa do trigo. Cultivo de trigo. Sistema de produção: adubação e calagem. [Sl.: s.n], 2009b. (Circular, n. 4).

GARBUGLIO, D. D. VI Reunião da Comissão Brasileira de Pesquisa de Trigo e Triticale. Informações técnicas para a safra 2013: trigo e triticale. Londrina: Instituto Agronômico do Paraná, 2013. 220 p.

FANCELLI, A. L.; DOURADO NETO, D. Produção de milho. Guaíba: Agropecuária, 2000. 360 p.

FERREIRA, A. O.; SÁ, J. C. M.; BRIEDIS, C.; FIGUEIREDO, A. G. Desempenho de genótipos de milho cultivados com diferentes quantidades de palha de aveia-preta e doses de nitrogênio. Pesquisa Agropecuária Brasileira, Brasília, v. 44, n. 2, p. 173-179, 2009. 
FERREIRA, D. F. Análises estatísticas por meio do Sisvar para Windows versão 4.0. In: REUNIÃO ANUAL DA REGIÃO BRASILEIRA DA SOCIEDADE INTERNACIONAL DE BIOMETRIA, 45., 2000. São Carlos. Anais... São Carlos:UFSCar, 2000. p. 255-258.

FONTOURA, S. M. V.; BAYER, C. Volatilização de amônia em plantio direto na região centro-sul do Paraná. Revista Brasileira de Ciência do Solo, Viçosa, MG, v. 34, n. 5, p. 1677-1684, 2010.

GAVA, G. J. C.; OLIVEIRA, M. W.; SILVA, M. A.; JERÔNIMO, E. M.; CRUZ, J. C. S.; TRIVELIN, P. C. O. Produção de fitomassa e acúmulo de nitrogênio em milho cultivado com diferentes doses de ${ }^{15} \mathrm{~N}$-uréia. Semina: Ciências Agrárias, Londrina, v. 31, n. 4, p. 851$862,2010$.

LARA CABEZAS, W. A. R.; TRIVELIN, P. C. O.; KONDORFER, G. H.; PEREIRA, S. Balanço da adubação nitrogenada sólida e fluida de cobertura na cultura do milho, em sistema plantio direto no triângulo mineiro (MG). Revista Brasileira de Ciência do Solo, Viçosa, MG, v. 24, n. 2, p. 363-376, 2000.

LARACABEZAS, W.A. R.; SOUZA, M. A. Volatilização de amônia, lixiviação de nitrogênio e produtividade de milho em resposta à aplicação de misturas de uréia com sulfato de amônio ou com gesso agrícola. Revista Brasileira de Ciência do Solo, Viçosa, MG, v. 32, n. 6, p. 2331-2342, 2008.

MEGDA, M. M.; BUZETTI, S.; ANDREOTTI, M.; TEIXEIRA FILHO, M. M. C.; VIEIRA, M. X. Resposta de cultivares de trigo ao nitrogênio em relação às fontes e épocas de aplicação sob plantio direto e irrigação por aspersão. Ciência e Agrotecnologia, Lavras, v. 33, n. 4, p. 1055-1060, 2009.

MELO,A. V.; GALVÃO, J. C. C.; BRAUN, H.; SANTOS, M. M.; COIMBRA, R. R.; SILVA, R. R.; REIS, W. F. Extração de nutrientes e produção de biomassa de aveia preta cultivada em solo submetido a dezoito anos de adubação orgânica e mineral. Semina: Ciências Agrárias, Londrina, v. 32, n. 2, p. 411-420, 2011.

MENEGHIN, M. F. S.; RAMOS, M. L. G.; OLIVEIRA, S. A.; RIBEIRO JÚNIOR, W. Q.; AMABILE, R. F. Avaliação da disponibilidade de nitrogênio no solo para o trigo em Latossolo Vermelho do Distrito Federal. Revista Brasileira de Ciência do Solo, Viçosa, MG, v. 32, n. 5, p. 1941-1948, 2008.

MURAISHI, C. T.; LEAL, A. J. F.; LAZARINI, E.; RODRIGUES, L. R.; GOMES JUNIOR, F. G. Manejo de espécies vegetais de cobertura de solo e produtividade do milho e da soja em semeadura direta. Acta Scientiarum Agronomy, Maringá, v. 27, n. 2, p. 199-207, 2005.
OATES, K. M.; KAMPRATH, E. J. Sulfur fertilization of winter wheat grown on deep sandy soils. Soil Science Society of American Journal, Madison, USA, v. 49, p. 925-927, 1985.

OLIVEIRA, J. M. S.; CAIRES, E. F. Adubação nitrogenada em cobertura para o milho cultivado após aveia preta no sistema plantio direto. Acta Scientiarum Agronomy, Maringá, v. 25, n. 2, p. 351-357, 2003.

OLIVEIRA, E. Sugestão de adubação e calagem para culturas de interesse econômico no Paraná. Londrina, Instituto Agronômico do Paraná, 2003. 30 p. (Circular, n. 128).

OZORIO FILHO, B. D.; REINHEIMER, D. S.; SILVA, L. S.; KAMINSKI, J.; DIAS, G. F. Deposição do enxofre atmosférico no solo pelas precipitações pluviais e respostas de culturas à adubação sulfatada em sistema plantio direto. Ciência Rural, Santa Maria, v. 37, n. 3, p. 712-719, 2007.

SANGOI, L.; ERNANI, P. R.; SILVA, P. R. F. da. Maize response to nitrogen fertilization timing in two tillage system in a soil with high organic matter content. Revista Brasileira de Ciência do Solo, Viçosa, MG, v. 31, n. 3, p. 507-517, 2007.

SANTI, A.; AMADO, T. J. C.; COSTA, J. A. A. Adubação nitrogenada na aveia preta. I. Influência na produção de matéria seca e ciclagem de nutrientes sob sistema plantio direto. Revista Brasileira de Ciência do Solo, Viçosa, MG, v. 27, n. 6, p. 1075-1083, 2003.

SECRETARIA ESTADUAL DE ABASTECIMENTO - SEAB. Grãos, algodão e outras culturas - Paranáevolução da área colhida e da produção obtida. Curitiba: SEAB: DERAL, 2013. Disponível em: <http://www. pr.gov.br/seab>. Acesso em: 14 fev. 2013.

SILVA, A. A.; SILVA, P. R. F.; SANGOI, L.; PIANA, A. T.; STRIEDER, M. L.; JANDREY, D. B.; ENDRIGO, P. C. Produtividade do milho irrigado em sucessão a espécies invernais para produção de palha e grãos. Pesquisa Agropecuária Brasileira, Brasília, v. 43, n. 8, p. 987-993, 2008.

SILVA, A. A.; SILVA, P. R. F.; SUHRE, E.; ARGENTA, G.; STRIEDER, M. L.; RAMBO, L. Sistemas de cobertura de solo no inverno e seus efeitos sobre o rendimento de grãos do milho em sucessão. Ciência Rural, Santa Maria, v. 37, n. 4, p. 928-95, 2007.

SILVA, M. A. G. ; MANNIGEL, A. R.; PORTO, S. M. A.; MUNIZ, A. S.; MARCHETTI, M. E.; BERTANI, R. M. A.; NOLLA, A. Ammonium sulfate application for maize crops under no tillage. Bragantia, Campinas, v. 71, n. 1, p. 90-97, 2012. 
SILVA, M. A. G.; MUNIZ, A. S.; MANNIGEL, A. R.; PORTO, S. M. A.; MARCHETTI, M. E.; NOLLA, A.; GRANNEMANN, I. Monitoring and evaluation of need for nitrogen fertilizer topdressing for maize leaf chlorophyll readings and the relationship with grain yield. Brazilian Archives of Biology and Technology, Curitiba, v. 54, n. 4, p. 665-674, 2011.

SILVA, M. A. G.; PORTO, S. M. A.; MANNIGEL, A.; MUNIZ, A. S.; MATA, J. D. V. da; NUMOTO, A. Y. Manejo da adubação nitrogenada em relação ao crescimento da aveia preta.e produtividade do milho em plantio direto. Acta Scientiarum Agronomy, Maringá, v. 31, n. 2, p. 275-281, 2009.

SORATTO, R. P.; PEREIRA, M.; COSTA, T. A. M.; LAMPERT, V. N. Fontes alternativas e doses de nitrogênio no milho safrinha em sucessão à soja. Revista Ciência Agronômica, Fortaleza, v. 41, n. 4, p. 511-518, 2010.

SOUZA, J. A.; BUZETTI, S.; TARSITANO, M. A. A.; VALDERRAMA, M. Lucratividade do milho em razão das fontes, doses e épocas de aplicação de nitrogênio. Revista Ceres, Viçosa, MG, v. 59, n. 3, p. 321-329, 2012.
TEIXEIRA FILHO, M. C. M.; BUZETTI, S.; ANDREOTTI, M.; ARF, O.; BENETT, C. G. S. Doses, fontes e épocas de aplicação do nitrogênio em trigo irrigado em plantio direto. Pesquisa Agropecuária Brasileira, Brasília, v. 45, n. 8, p. 797-804, 2010.

TEDESCO, M. J.; GIANELLO, C.; ANGHINONI, I.; BISSANI, C. A.; CAMARGO, F. A. O.; WIETHÖLTER, S. (Ed.). Manual de adubação e de calagem para os estados do Rio Grande do Sul e de Santa Catarina. Porto Alegre: Sociedade Brasileira de Ciência do Solo Comissão de Química e Fertilidade do Solo, 2004. 400 p.

TIECHER, T.; SANTOS, D. R.; RASCHE, J. W.; BRUNETTO, G.; MALLMANN, F. J. K.; PICCIN, R. Resposta de culturas e disponibilidade de enxofre em solos com diferentes teores de argila e matéria orgânica submetidos à adubação sulfatada. Bragantia, Campinas, v. 71, n. 4, p. 518-527, 2012. 